\title{
MONITORING OF CURRENT COLLECTORS ON THE RAILWAY LINE
}

\author{
Krzysztof Karwowski, Mirosław Mizan, Dariusz Karkosiński \\ Faculty of Electrical and Control Engineering, Gdańsk University of Technology, Poland \\ Submitted 28 November 2014; resubmitted 9 March 2015; accepted 1 June 2015; \\ published online 29 February 2016
}

\begin{abstract}
Proper cooperation the current collectors and the overhead line is a pre-requisite for reliable and safe operation of railway transport. Instances of maladjustment and, in some cases, damage to the current collectors, occur between periodic inspections of the rolling stock. In order to detect such anomalies quickly, the test stand was developed, with the aim of monitoring the technical state of the current collectors under operating conditions. The detection procedure is based on the monitoring and analysis of contact wire uplift caused by the pressure of the current collector, as the train passes through the measuring point located on the railway line and is designed with the aim of detecting collectors with incorrect values of a contact force.
\end{abstract}

Keywords: catenary; pantograph; double pantographs; dynamic performance; simulation; monitoring system; railway.

\section{Introduction}

The catenary is still the most effective way of supplying power to electric railway vehicles. Increase in a vehicle's speed, raises the power consumption and thus, requires proper cooperation between the current collectors of vehicles and the overhead contact line (Szeląg, Maciołek 2013). Even under normal operating conditions, monitoring of the contact force of the pantograph head and the wire, is required, to facilitate longer maintenance cycles and improved reliability of systems (Mizan et al. 2013).

Various resources contain a large number of papers, which focus on studies of catenary-pantograph interactions. Research papers, which have been released recently, concern the modelling of these interactions - especially in the context of high-speed trains (Facchinetti, Bruni 2012; Pombo, Ambrósio 2013; Pombo et al. 2009; Zhou, Shen 2011). They treat the catenary contact wire with finite elements, based on the absolute nodal co-ordinate formulation, while the pantograph is approached as a full 3D multi-body model (Benet et al. 2013).

Due to complex challenges involved in the modelling of a catenary-pantograph system, many researchers suggest an approach involving a co-simulation between the finite discretization of the catenary, and the multi-body representation of the pantograph (Ambrósio et al. 2012; Rauter et al. 2007). This demonstrates how the coupling between finite element software and multi-body software can be efficiently achieved, in or- der to simulate the interaction in catenary-pantograph systems.

The dynamic performance of the simple catenary and pantograph structure was simulated by Zhou and Zhang (2011). It was determined that the structural parameters, including the stiffness and damping, static force of the pantograph, and the tension of the contact wire, all, have a strong influence on interactions between the pantograph and catenary system. Several important efforts made, have commented on the quality of the catenary-pantograph contact by Pombo and Ambrósio $(2012,2013)$.

Another deterministic factor seems to involve the evaluation of the technical state of individual pantographs on the railway line (Bucca et al. 2011). Although the state of current collectors is regularly checked by railway companies, cases of maladjustment or even damage, has been known to occur - occasionally and unpredictably - between periodic inspections of the rolling stock. The quick detection of such anomalies helps to avoid the major damage of components of the overhead line, and in some critical cases, may even prove to prevent train accidents. Failures of the catenary or collectors are rare. However, costs associated with repairing damages and associated costs involving delayed trains, are relatively high (Kiessling et al. 2009; Tanarro, Fuerte 2011).

A few publications have been published in the context of the measurement systems for monitoring cate- 
nary-pantograph interactions (Bocciolone et al. 2013). For instance, the non-contact sensor for monitoring catenary-pantograph interaction system - described in (Luna Vázquez et al. 2010) - bases its operation on optical devices. The system measures the vertical position of the contact wire, by use of a line-scan camera, focused on the contact wire in conjunction with a reference background screen.

One possible - and relatively easy-to-determine indicator of a faulty collector may be the value of the contact wire uplift, as a train passes a measurement point. The uplift value depends on the elasticity of the contact line and the contact force. The main component of the contact force is the pantograph static force, which is adjustable during maintenance and repairs performed at the depot. The aerodynamic component of the contact force depends on speed. It facilitates the reliable evaluation of the collector's state and is also necessary to measure the train velocity. The evaluation criteria for the measurement at a particular point of the catenary, is determined by analysing the waveform of contact wire uplift in relation to the speed, based on simulations and a series of experimental results. Of particular importance here, is the estimation of the static force of the collector. This value can easily be measured during the technical inspection of rolling stock. Based on the monitored results, it is possible to detect faulty or incorrectly adjusted current collectors. This paper presents the method of detecting such collectors, which is depicted in Fig. 1. Based on these assumptions, the measuring station for permanent monitoring of traction current collectors has been developed and implemented on selected railway line in Poland.

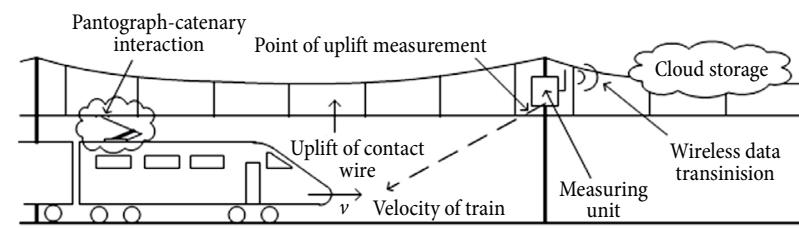

Fig. 1. Concept of monitoring station for detection of faulty current collectors on railway line

\section{Simulation Research}

In order to determine the typical waveform of the uplift of contact wire, during the trains' passage through the measurement point, simulations were performed. Relations between the static force and the maximum value of the contact wire uplift have now been identified. The purpose of these studies was the implementation of guidelines for the selection of the measuring equipment parameters and the preliminary design of algorithms, to aid with the evaluation of the collectors' technical states. One of the important issues was to investigate the uplift effects caused by the presence of two elevated train collectors, placed within a short distance of each other. On a standard railway line, trains are often operated by double locomotive or suburban electric multiple units, with several raised collectors - with the trains operating at a fairly low speed. For that reason, it was recommended to check the impact of such conditions, on the results of wire uplift caused by the second and subsequent collectors in the train.

In other systems, this type of monitoring can only be realized for the first collector on the train (Schorno et al. 2011). Performed simulations have established the critical ranges of distance between the current collectors on the train - in relation to speed - that allow for their correct assessments.

Overhead contact lines with moving current collectors, is a very complex mechanical system. In order to simulate the uplift of the wire at a network specific location, simplified models of catenary lines and current collectors, that consist of composed elements of a certain mass, elasticity and damping factors, are generally utilized (Zhou, Zhang 2011).

A pantograph itself is most often modelled as a system of one, two or three mass. In this context, in order to simulate dynamic vertical displacement of the contact wire, the simplified three-mass model consisting of a set of current collectors and catenary, was created. The structure of the model is presented in Fig. 2, where:

$m_{l}$-equivalent mass of line section;

$m_{h}$ - mass of pantograph head;

$m_{a}$ - mass of pantograph arms;

$c_{l}, c_{h}, c_{a}$-damping of traction line, pantograph head and arms;

$k_{l}, k_{h}, k_{a}$-spring constant of line, pantograph head and arms;

$y_{l}, y_{p}$-position (in vertical direction) of contact wire and of the upper end of the pantograph arms;

$F_{u}$-equivalent force component that causes the up-lift of contact wire at the measurement point;

$F_{f}$ - friction in the joints of the pantograph arms;

$v$ - train velocity;

$t_{u n}$ - time duration of exertion of the force $F_{u}$;

$l_{1-2}$ - distance between two raised pantograph $p_{1}$ and $p_{2}$ in a train;

$t_{\text {max 1-2 }}$-time between occurrence of peaks of the forces $F_{u 1}$ and $F_{u 2}$.

The model for a single current collector is described by equations:

$$
\begin{aligned}
& \left(m_{l}+m_{h}\right) \frac{d^{2} y_{l}}{d t^{2}}+c_{l} \frac{d y_{l}}{d t}+ \\
& c_{h}\left(\frac{d y_{l}}{d t}-\frac{d y_{p}}{d t}\right)+k_{l} y_{l}+ \\
& k_{h}\left(y_{l}-y_{p}\right)+\left(m_{l}+m_{h}\right) g=0 ; \\
& m_{p} \frac{d^{2} y_{p}}{d t^{2}}+c_{p} \frac{d y_{p}}{d t}+ \\
& c_{h}\left(\frac{d y_{p}}{d t}-\frac{d y_{l}}{d t}\right)+k_{p} y_{p}+ \\
& k_{h}\left(y_{p}-y_{l}\right)+m_{p} g= \\
& F_{u}(t)+\operatorname{sgn}\left(\frac{d y_{p}}{d t}\right) F_{f} .
\end{aligned}
$$




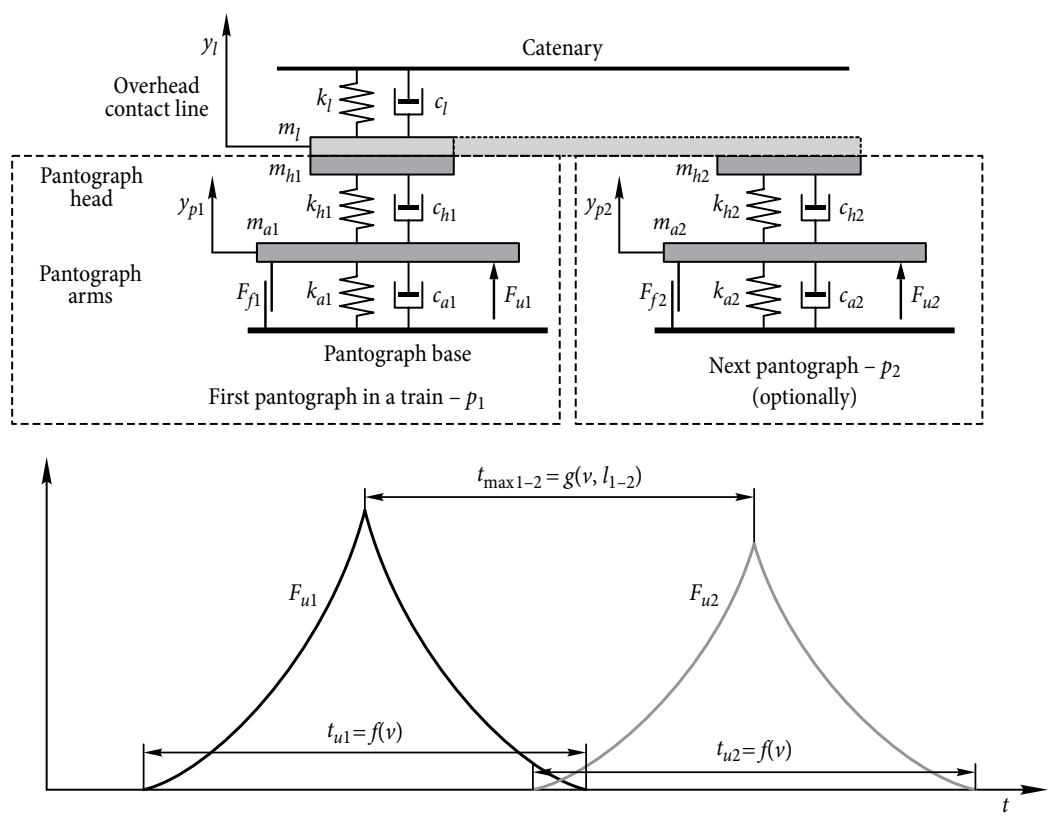

Fig. 2. Simplified model of a set of train pantographs and catenary - used to simulate contact wire uplift

Eq. (1) relates to a set: pantograph head and overhead catenary; Eq. (2) applies to the arms of the pantograph. The parameter values used in the model are given in Table 1.

The model maps change in the position of the contact wire and pantograph in a vertical direction only. To simplify the model, changes in the force lifting the contact wire at the point of uplift measurement, are modelled through a special time-distribution of hypothetically equivalent force component $F_{u}$. The source of the force component is the pressure of the pantograph exerted on the contact wire, at a certain distance from this point. This force increases when the pantograph approaches the point of measurement, and decreases as it moves away. It also includes the aerodynamic force component that is dependent on train velocity $v$.

Table 1. Values of a model main parameters

\begin{tabular}{|c|c|c|l|}
\hline Symbol & Unit & Value & \multicolumn{1}{|c|}{ Designation } \\
\hline$m_{l}$ & $\mathrm{~kg}$ & 130.4 & equivalent mass of line section \\
\hline$m_{h}$ & $\mathrm{~kg}$ & 18.4 & mass of pantograph head \\
\hline$m_{a}$ & $\mathrm{~kg}$ & 17.0 & mass of pantograph arms \\
\hline$k_{l}$ & $\mathrm{~N} / \mathrm{m}$ & 2300 & spring constant of traction line \\
\hline$k_{h}$ & $\mathrm{~N} / \mathrm{m}$ & 600 & $\begin{array}{l}\text { spring constant of pantograph } \\
\text { head }\end{array}$ \\
\hline$k_{a}$ & $\mathrm{~N} / \mathrm{m}$ & 280 & $\begin{array}{l}\text { spring constant of pantograph } \\
\text { arms }\end{array}$ \\
\hline$c_{l}$ & $\mathrm{Ns} / \mathrm{m}$ & 1 & damping of traction line \\
\hline$c_{h}$ & $\mathrm{Ns} / \mathrm{m}$ & 4 & damping of pantograph head \\
\hline$c_{a}$ & $\mathrm{Ns} / \mathrm{m}$ & 300 & damping of pantograph arms \\
\hline$F_{u(m a x)}$ & $\mathrm{N}$ & $70-140$ & $\begin{array}{l}\text { equivalent static force } \\
\text { component (maximum value) }\end{array}$ \\
\hline$F_{f}$ & $\mathrm{~N}$ & $6-10$ & $\begin{array}{l}\text { friction in the joints of the } \\
\text { pantograph arms }\end{array}$ \\
\hline
\end{tabular}

The waveform of force $F_{u}$ is determined in accordance with a predetermined vehicle velocity. The $t_{u n}$ is a time period during the exertion of the pressure of pantograph $n$ is noticeable at the measurement point. It depends on $v$ and on the known length of the adjacent sections of catenary. In order to determine the waveform of force $F_{u}$, a series of experiment results carried out on the overhead line of a very similar construction - and their results - were taken into account. For the train with two or more raised pantographs, the part of the model related to the current collector is duplicated, and the waveforms of $F_{u n}$ for the subsequent pantographs are respectively shifted in time. The time $t_{\max 1-2}$ between the occurrence of peaks on the waveforms $F_{u 1}$ and $F_{u 2}$ is dependent on a train's velocity $v$ and on a distance $l_{1-2}$ between pantographs $p_{1}$ and $p_{2}$. Other parameters like the force $F_{u 2}$ can be set independently.

The constructed model is easy to implement in MatLab. The aim of simulation research was to determine the expected range and slew rate of the contact wire uplift, under varying operating conditions on track. Diversely adjusting static forces of current collectors, and the inclusion of values that significantly deviate from normative requirements - at different train speeds - are of particular significance, in this respect. This allows for the selection of requisite measuring instruments, based on the required dynamics, range and resolution. The second objective was to examine the possibility of evaluating the forces separately, based on various sets of pantographs raised together in the train - according to their mutual distance and drive speed.

Fig. 3 shows the contact wire uplift waveforms for trains with very low speeds, with different adjusted pantograph static force values, provided as input. Here, the near-linear relationship between the peak value of the uplift and the static force, is observable. The arrow on 
the graph indicates the moment in time in which the current collector passes the point of uplift measurement (Fig. 1). In addition, the simulated value of the static force is included in the illustration.

Fig. 4 depicts the influence of the train's speed, on the waveform shape and on the maximum value of the uplift. Higher speeds result in the increase of the amplitude of excited vibrations of the wire, but their impact on the uplift peak value remains small. There is an aerodynamic component of the contact force, which slightly increases the value of the uplift. The uplift waveforms for different trains have intentionally been shifted horizontally (i.e. along the time axis), in order to increase the readability of graphs.

Fig. 5 shows the effects caused by interactions of two raised pantographs and the contact line. The correlation between parameters such as driving speed, distance between pantographs and their force setting, hinders the independent evaluation of each one. By driving at low speeds of up to $20 \mathrm{~m} / \mathrm{s}$ and at distances greater than $30 \mathrm{~m}$, the evaluation may be carried out in a similar manner to instances involving a single pantograph. In other cases, such results are not reliable. In particular, this can be seen in Fig. 5b, where at speed of $34.7 \mathrm{~m} / \mathrm{s}$ and at distance of $24 \mathrm{~m}$ between raised pantographs, the uplift waveform does not show two separate peaks. In

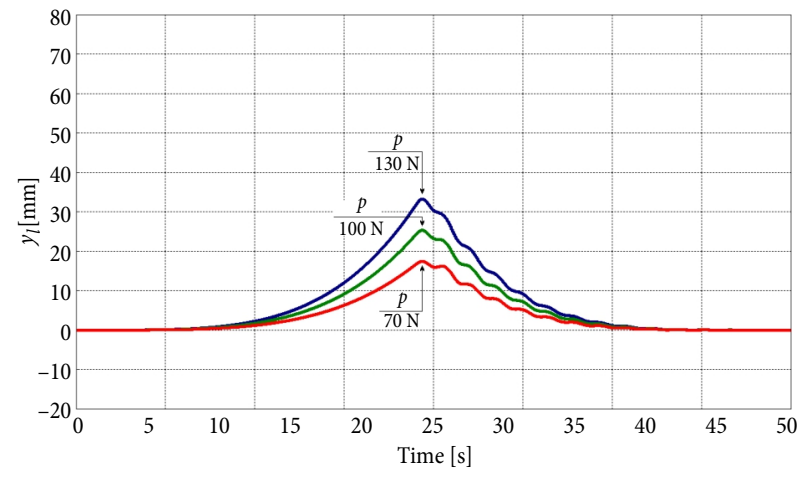

Fig. 3. Simulation result of contact wire uplift waveform for three trains of speed $v=3.6 \mathrm{~m} / \mathrm{s}$, each with one raised pantograph with different adjusted static forces

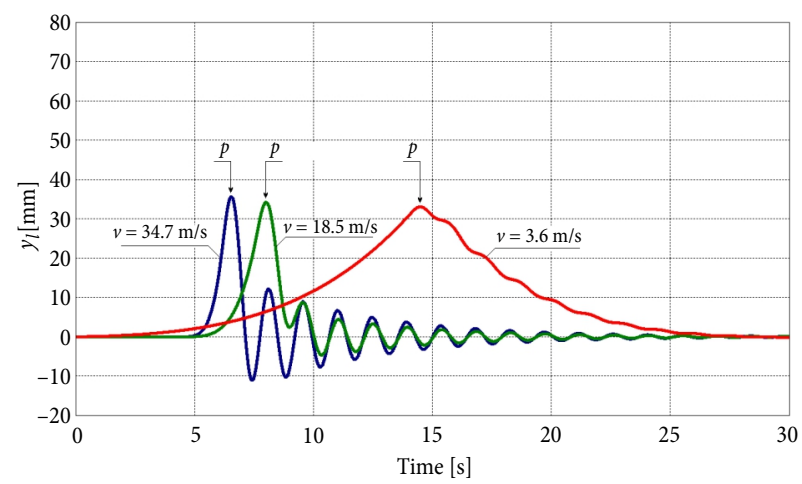

Fig. 4. Simulation result of contact wire uplift waveform for three trains, each with one raised pantograph of static force $F_{u}=130 \mathrm{~N}$, distinguished by different train speeds this case, the conclusion that can be deduced is the cumulative total force of both pantographs.

Strong differences in pressure forces of the subsequent current collectors do not preclude their independent evaluation. Such an example is shown in Fig. 6. With extremely varying values of the force, the automatic localization of the passing point of collector with a smaller force may be difficult to determine, due to the lack of a conclusive peak value. However, the algorithm can then be adjusted manually by an operator, basing on observations obtained from the image recording.

a)

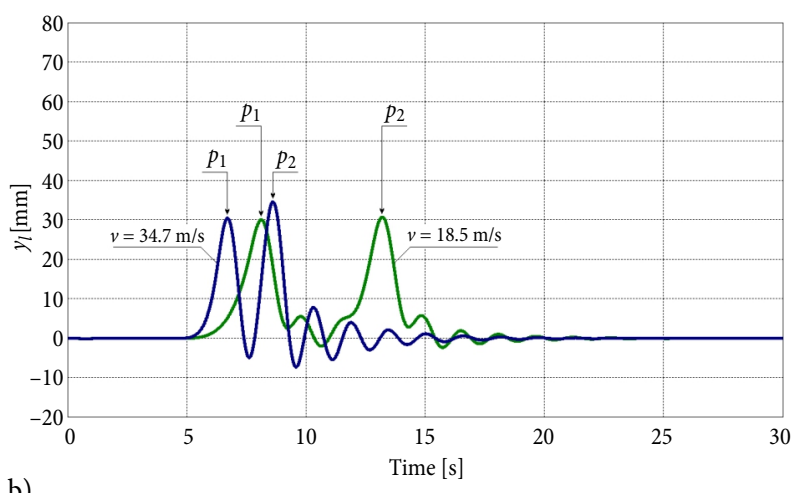

b)

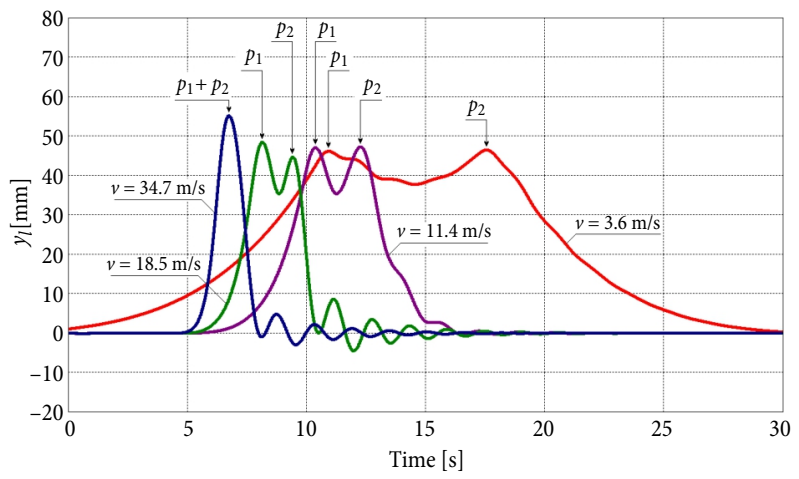

Fig. 5. Simulation results of contact wire uplift waveform for: a - two trains, with raised pantographs $p_{1}, p_{2}$ spaced at $l_{1-2}=$ $70 \mathrm{~m}$, of static force $F_{u 1}=F_{u 2}=100 \mathrm{~N} ; \mathrm{b}$ - four trains, with raised pantographs $p_{1}, p_{2}$ spaced at $l_{1-2}=24 \mathrm{~m}$ of static force $F_{u 1}=F_{u 2}=130 \mathrm{~N}$

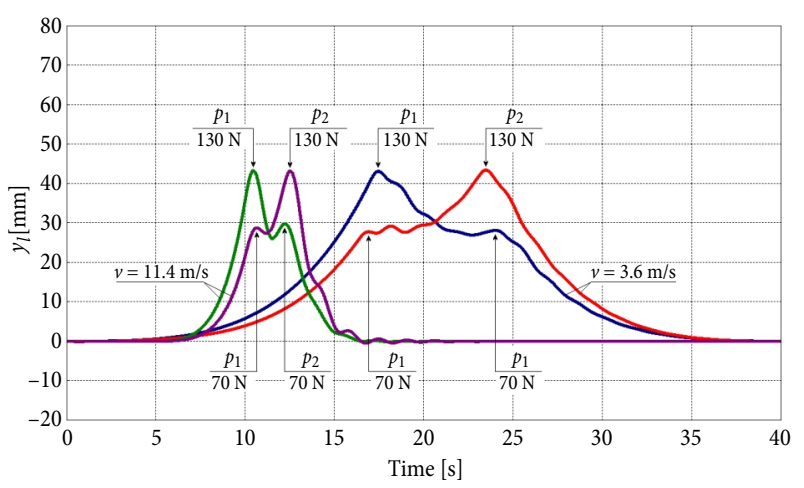

Fig. 6. Simulation results of contact wire uplift waveform for four trains, each with two raised pantographs $p_{1}, p_{2}$ spaced at $l_{1-2}=24 \mathrm{~m}$ of strongly differing static forces: $F_{u 1-\mathrm{A}}=F_{u 2-\mathrm{B}}=$ $F_{u 1-\mathrm{C}}=F_{u 2-\mathrm{D}}=130 \mathrm{~N}$ and $F_{u 2-\mathrm{A}}=F_{u 1-\mathrm{B}}=F_{u 2-\mathrm{C}}=F_{u 1-\mathrm{D}}=70 \mathrm{~N}$ 


\section{Monitoring Station on the Railway Line}

The practical implementation of the monitoring station on the railway line - in accordance with the concept shown in Fig. 1 - is illustrated in Fig. 7.

Measuring of the uplift is realized via a laser displacement meter and the reflective plate fixed to the contact wire. The laser meter is mounted to the support structure of the catenary. The dimensions of the reflective plate result from the thermal length change of the wire and the amplitude of its horizontal vibrations. The detection of a train and measurement of its speed is realized using a laser range finder. It enables the tracking of a moving train within a range of approximately $60 \mathrm{~m}$ to $200 \mathrm{~m}$ from the measurement point. The laser distance meters, the control computer and other electronic devices - including elements of the power supply - are placed in distribution boxes, to protect against environmental conditions. By using high resolution IP camera directed along the track, three photographs of an oncoming train are being automatically taken, so as to enable easy identification of the type of the vehicle and recognition of the raised pantograph. Example of photos from the camera is shown in Fig. 8.

The measurements and data acquisition process is continuously controlled by the local computer. The software of this computer was created using the LabView programming environment. It is note-worthy, that data acquisition of the contact wire uplift value occurs only when a train passes a measurement station area. The program creates and formats the measurement data files along with other related image files (including train

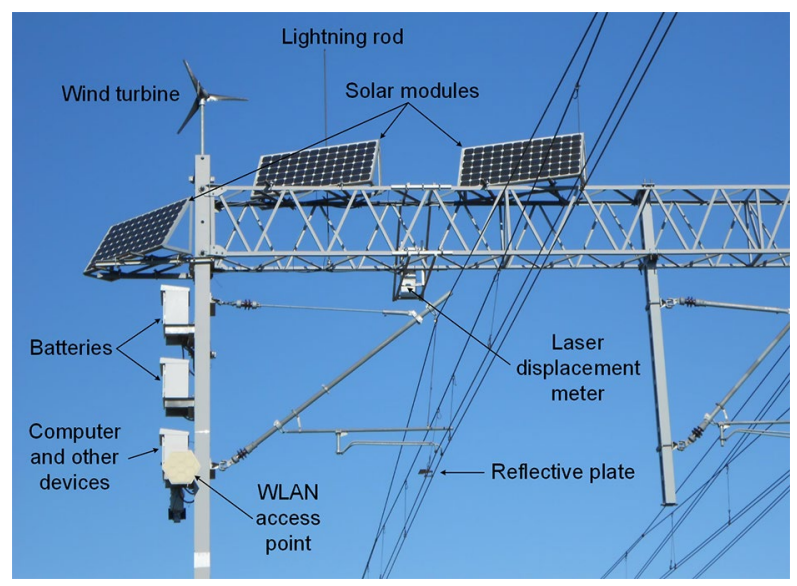

Fig. 7. Measuring station on catenary support structure

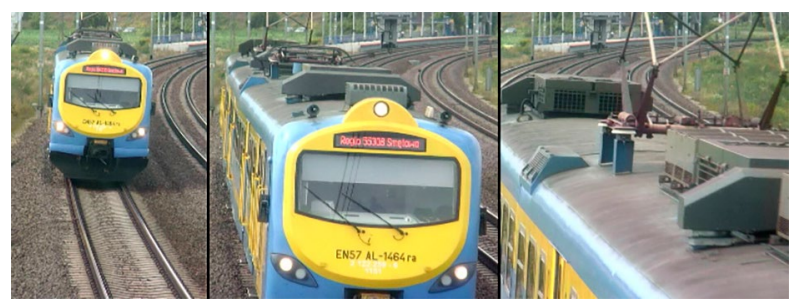

Fig. 8. Set of three camera images taken, for identification of vehicle and raised pantograph photos), and then sends them - via a WLAN - to the cloud storage. This facilitates the tracking and analysis of the results obtained from monitoring, from any remote location and a computer with internet access.

The specialized software was created, to aid with the monitoring and evaluation of the current collector force. This software has two basic modes of operation. By continuously monitoring of current collectors - as new data is received - the software automatically initiates the processing and analysis of the results. During the first pass, the program detects and locates raised collectors on the train, based on the waveform of contact wire uplift. During the second pass, the program calculates the estimated value of static force of each pantograph, taking into account the speed of the train, and the cumulative effects of the impact of several current collectors.

If the calculated value does not exceed the permitted range, the force estimation results are appended to the data file and the program waits for new data from the next passing of a train. Otherwise, the alarm sounds, indicating the detection of an incorrectly adjusted or faulty current collector. The alarm needs to be acknowledged by the user. Thus, the program can be executed in the background, needing user input, only in the case of detection of a malfunction of the pantograph - allowing its immediate response.

The second mode involves manually opening and processing the data file, at any time and in any order. The results of the simulation tests were the basis of the preliminary design of the algorithm, used to calculate the pantographs static forces. In most cases, results of real measurements, display a high degree of consistency with the simulation results yielded. This applies especially to scenarios involving trains with one raised pantograph; but also applies to cases involving multiple raised pantographs, where velocity is relatively low. Comparison of contact wire uplift waveforms in such cases - obtained from the model and measurements, are shown in Fig. 9.

Due to the complex relationship between many factors and their influence - some of which are related to the specific location of the measurement - the final formulae of the calculation algorithm implemented in the program, is based to a large degree, on results of experimental trials. During the implementation of the monitoring station, a number of scaling runs were carried out, using a specially prepared locomotive with varyingly adjusted static force values for pantographs. In addition, for a dozen locomotives being in continuous traffic, the measurements of static characteristics of the current collectors were carried out in the depot, and the obtained data was compared with estimated results generated by the monitoring station; which helped with the correction and improvement of the program algorithm. It should be emphasized, that due to the impact of a number of partially non-deterministic factors, on the waveform of contact wires uplift, the estimated value of the collector static force is always likely to be approximate. Consequently, a practical approach to evaluation of the current collector was introduced as a four-level 
a)

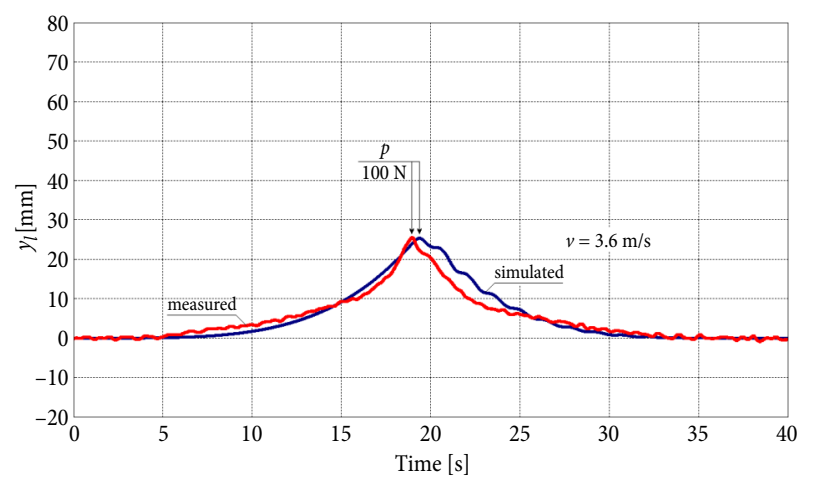

b)

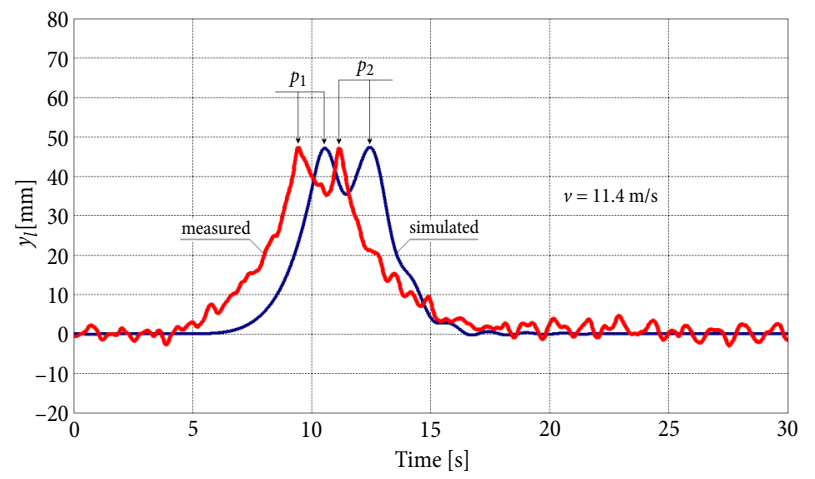

Fig. 9. Comparison of simulation and measurement results of contact wire uplift waveform for: a - train with one raised pantograph $p$ of static force $F_{u}=100 \mathrm{~N} ; \mathrm{b}-$ train with two raised pantographs $p_{1}, p_{2}$ spaced at $l_{1-2}=24 \mathrm{~m}$ of static force

$$
F_{u 1}=F_{u 2}=130 \mathrm{~N}
$$

score, ranging from 0 to 3 (level 0 - very good technical condition, 1 - satisfactory condition, 2 - requires a thorough check and adjustment at the next inspection in depot, 3 - needs an urgent inspection). This simplifies and assists with the decision on possible further actions to be taken by the user.

As a final result of the software development, the multi-criteria algorithm was created. It is partly based on the experimentally determined parameters of the decision-making process included in the look-up tables. This is applicable to both to the detection and location of the raised current collectors, as well as the calculated estimation of the value of the adjusted static force.

The program works interactively. Occasionally, in scenarios involving complex configurations of raised pantographs on a train, it may be necessary to manually correct the locations of current collector markers. The recorded images from the camera form the basis for this correction. After each manual change of a number of pantographs or their location in a train, the program automatically re-calculates the static forces and updates the score accordingly. An example of the results output (as a graph), generated by the data processing program, is shown in Fig. 10.

During the trial operation of the monitoring station, the calculation of the same pantograph static force

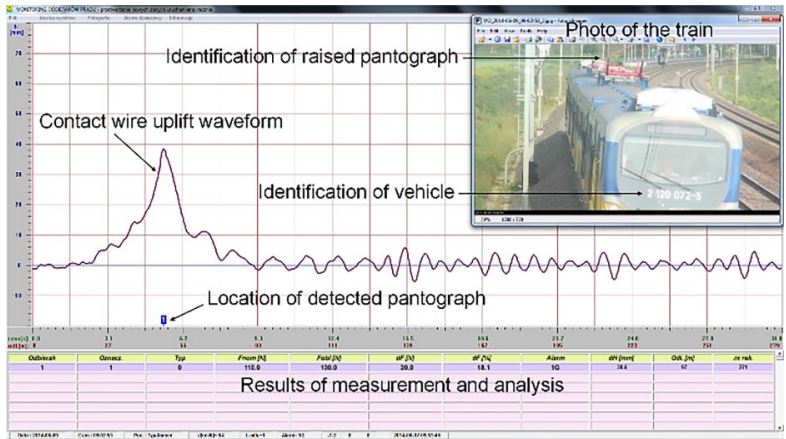

Fig. 10. Results output by program

a)

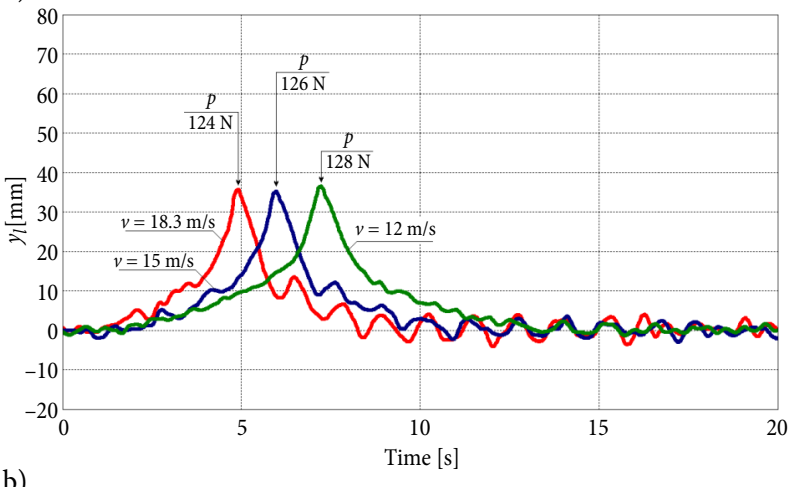

b)

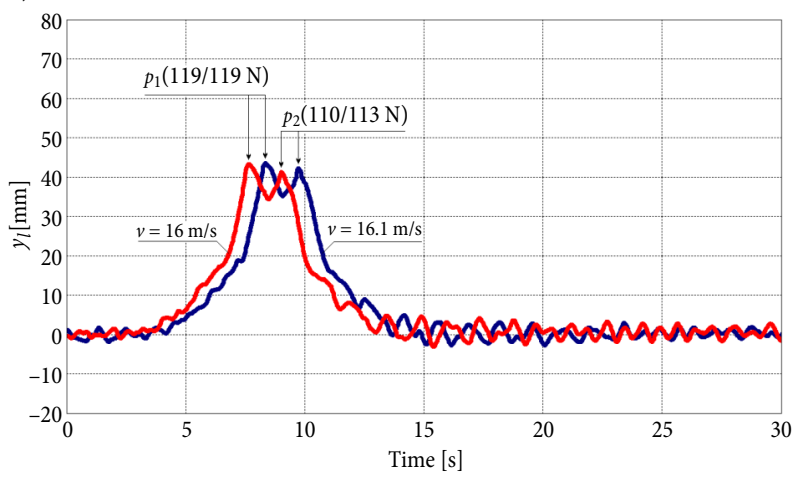

Fig. 11. Comparison of measurement results of contact wire uplift waveform for: a - locomotive with the same raised pantograph $p$ with small variations in speeds, registered in subsequent days; $\mathrm{b}$ - suburban train with two the same raised pantographs $p_{1}, p_{2}$ spaced at $l_{1-2}=24 \mathrm{~m}$, with equal speeds, registered twice on the same day

was repeated successively, on several days. Fig. 11 shows an example of the results for two trains - with one and two raised pantographs, registered in similar environmental conditions and at similar speeds. The differences between the calculated force values for each pantograph did not exceed $4 \mathrm{~N}$.

It was discovered that neither the ambient temperature, levels of sunlight, very heavy rain nor snow, impaired the accuracy of the measurement. On the other hand, strong gusts of wind were noted to cause a significant impact on the accuracy of estimation of the static force. 


\section{Examples of Original Uplift Waveforms}

During more than two years of operation of the monitoring system, there were registered trains utilized, with different configurations of raised current collectors, including many unusual combinations. It was detected, that a number of pantographs displayed significant deviations in static force, compared to normative values. Fig. 12 illustrates waveforms deviating well above the high and low thresholds. Such results, when obtained, qualify the pantograph to be assigned for urgent adjustment or repair in depot, as the calculated deviation in the setting of a static force, exceeds $30 \%$.

Fig. 13 shows examples of results obtained for nontypical configurations of pantographs in the train. The set of two locomotives with three or four raised pantographs - placed short distances apart - causes the accumulation of pressure forces on the short section of catenary, which leads to higher values of the uplift. Despite the low velocity (in cases Fig. 13a and Fig. 13b), the estimated values of the static force for all current collectors should be considered to be non-deterministic, because the scaling procedure of calculation algorithms has not been tested for such pantograph configurations.

The example presented in Fig. 14, concerns a single locomotive with both raised pantographs, which are inter-spaced at relatively short distances, of approximately $5 \mathrm{~m}$. This fact, combined with the relatively high velocity factor, often leads to the production of only one clearly marked local maximum in the waveform of wire uplift. This prevents the fully reliable calculation of forces for each current collector, as the program only detects one pantograph. It is though possible, to manually correct the number and location of collectors by the operator (refer to the added markers labelled $p_{n e}$ in Fig. 14); but the results of the evaluation of static forces still seem to remain uncertain and non-deterministic. It should be noted, however, that cases presented in Figs 13 and 14 occurring in the normal traffic conditions, are extremely rare.

Although the intended primary objective of the monitoring station is to detect the pantographs of improper pressure force, the analysis of recorded waveforms also facilitates the possibility of detection of other hardware failures too. For instance, observations have been made, of the appearance of anomalously strong oscillations of the contact wire, excited by current collectors passing through the measuring point. The oscillation amplitudes were much greater than ones produced by other trains running in similar weather conditions at the same speed and with the same force value for the pantograph. Such an example is shown in Fig. 15a. Simulation studies were performed by changing selected parameters of the pantographs model. They showed that a similar effect is achieved when the damping factor in the pantograph arm system is considerably reduced. The obtained results are shown in Fig. 15b. However, the formulation of appropriate criteria for the evaluation of this parameter - in this case - would necessitate long-term experimental comparative research.

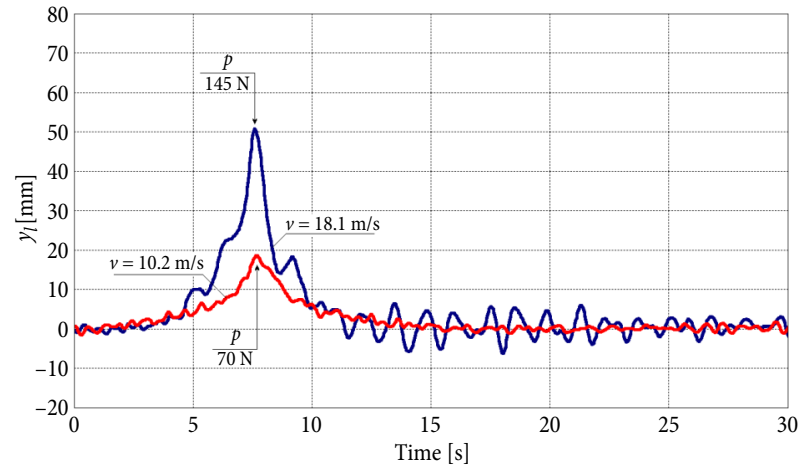

Fig. 12. Comparison of measurement results of contact wire uplift waveform for two trains, each with one raised pantograph p: the first train of excessive static force of current collector and an insufficient value for the second

a)

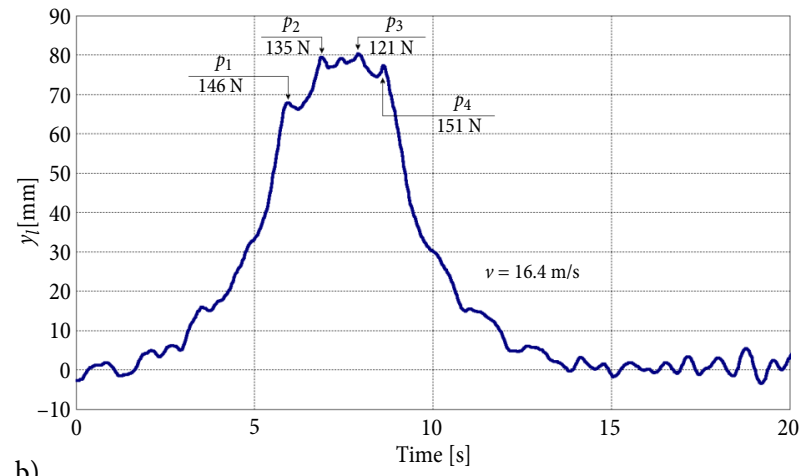

b)

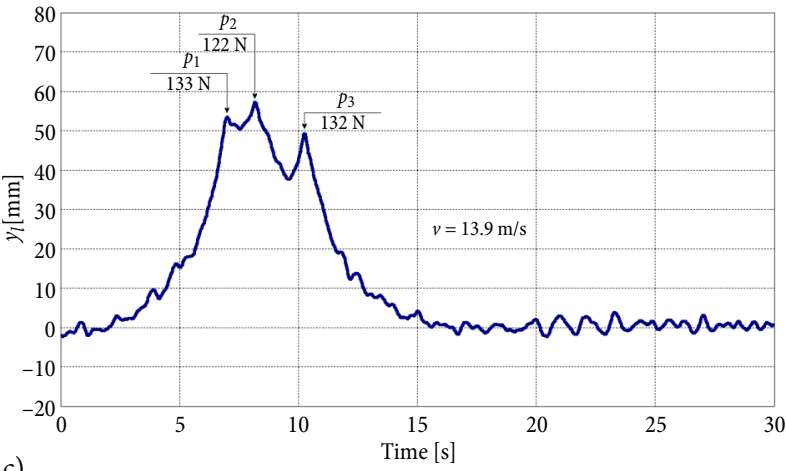

c)

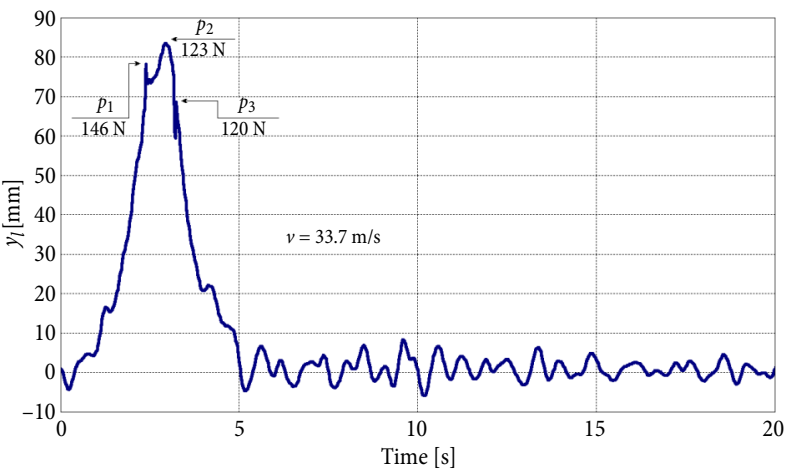

Fig. 13. Contact wire uplift waveform for trains with multiple raised pantographs $\mathrm{p}$ based on the following inter-spacing

criteria: a - four pantographs inter-spaced at $42 \mathrm{~m}$; $\mathrm{b}$ - three pantographs inter-spaced at $44 \mathrm{~m}$; c - three pantographs inter-spaced at $27 \mathrm{~m}$ 


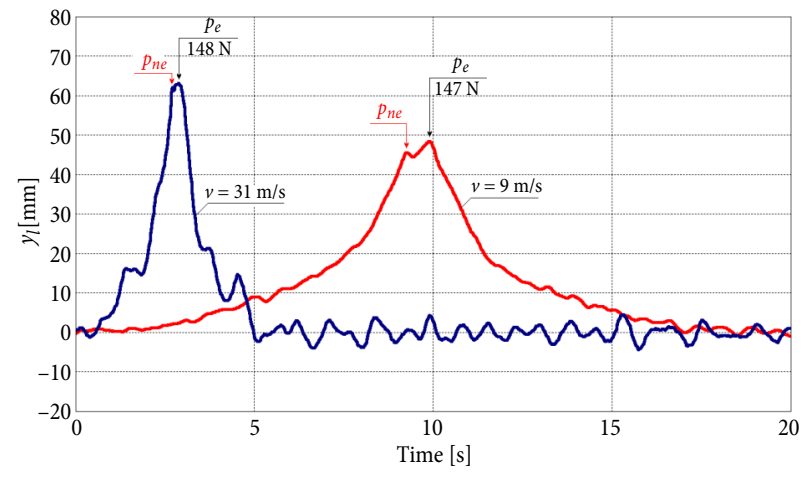

Fig. 14. Contact wire uplift waveform for the same locomotive with two raised pantographs inter-spaced extremely closely at $l_{1-2}=5 \mathrm{~m}$, tested in consecutive days with varying train speeds detected

a)

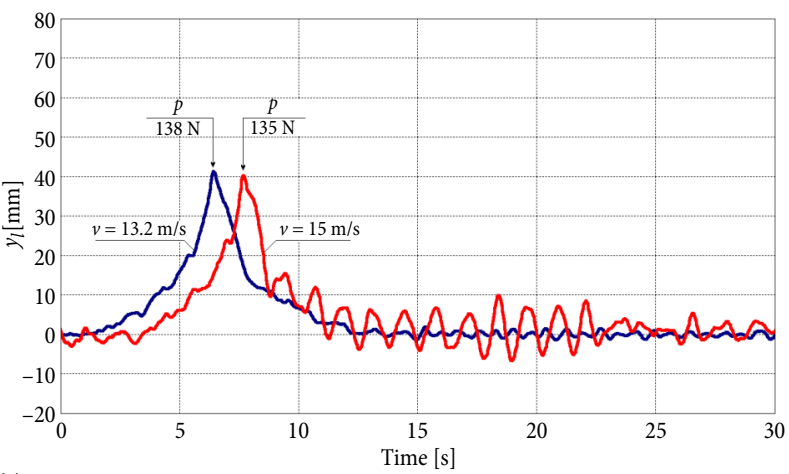

b)

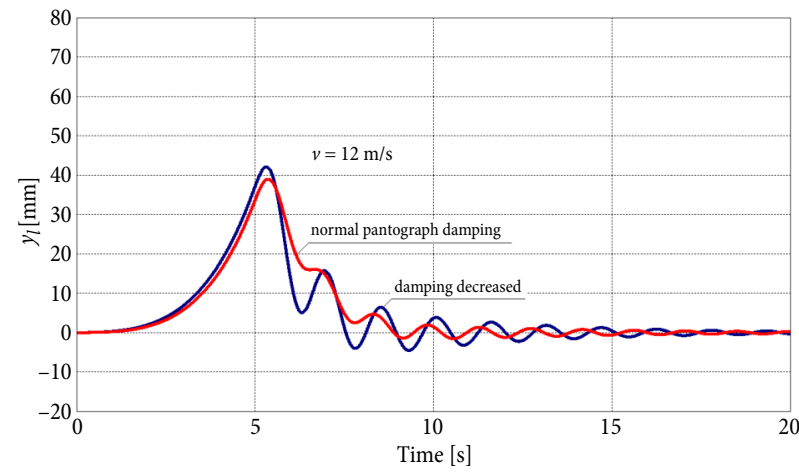

Fig. 15. Contact wire uplift waveform for trains with one raised pantograph $p$ : a - measurement results in cases of minimally and greatly excited oscillations of the wire; $\mathrm{b}$ - simulation results for correct and strongly reduced damping of the pantograph

\section{Conclusions}

The presented monitoring system of current collectors, allows the detection of defective or wrongly adjusted pantographs, directly on the railway line, in operational conditions. Presented simulation pantograph - the overhead contact line model has facilitated the development of the algorithm for estimating the collector static force. The average estimation error of this force is approximately $5 \%$. Computer generated evaluation of the pantograph static force, is an estimate and gives a recommendation for its thorough inspection at the depot, where static force should be accurately adjusted. The measurement process is automated, with the maintenance-free measurement station. The processing of data is also automated, but some specific cases would have to be verified by the operator. By placing the results in a cloud storage, the analysis of those results can be conducted on any computer connected to the Internet. With the exception of trains with unusual configurations of raised pantographs, the system is characterized by the ability to produce results, regardless of the lighting conditions, the weather or the speed of the train.

Measuring of the contact wire uplift is realized on thermal compensated overhead catenary line. Therefore, the change of the wire length due to winter and summer has not decreased the accuracy of static force estimation - it was experimentally verified.

By estimation of pantograph static force the influence of contact wire horizontal vibrations was neglected.

Statistical research has shown, that after more than two years of system operation, there has been some improvement in the technical conditions of the current collectors. The percentage of poorly regulated pantographs detected in line traffic, declined during this period about 5\%. This may be related to the direct use of the results of monitoring, which however, requires continuous collaboration between infrastructure managers and rail operators - this cooperation allows to eliminate the pantographs with a large deviation of the static force on its normative value. To some extent, this improvement could be a contributory psychological factor; i.e., the awareness that the condition of the current collectors is still controlled on-line, increases the attention of technical staff, during periodic inspections of rolling stock.

It is planned to expand the system, to a network of several measurement stations, deployed in various places on railway lines, which will transmit results to a central server. Functions of the measurement stations have to be extended for fault detection of pantograph contact strips. Appropriate experimental studies in this field based on high-speed 3D cameras have been already carried out in field conditions (Jarzebowicz, Judek 2014).

\section{References}

Ambrósio, J.; Pombo, J.; Pereira, M.; Antunes, P.; Mósca, A. 2012. A computational procedure for the dynamic analysis of the catenary-pantograph interaction in high-speed trains, Journal of Theoretical and Applied Mechanics 50(3): 681-699.

Bocciolone, M.; Bucca, G.; Collina, A.; Comolli, L. 2013. Pantograph-catenary monitoring by means of fibre Bragg grating sensors: Results from tests in an underground line, $\mathrm{Me}$ chanical Systems and Signal Processing 41(1-2): 226-238. http://dx.doi.org/10.1016/j.ymssp.2013.06.030

Bucca, G.; Collina, A.; Manigrasso, R.; Mapelli, F.; Tarsitano, D. 2011. Analysis of electrical interferences related to the current collection quality in pantograph-catenary interaction, Proceedings of the Institution of Mechanical Engineers, Part F: Journal of Rail and Rapid Transit 225(5): 483-500. http://dx.doi.org/10.1177/0954409710396786

Benet, J.; Cuartero, N.; Cuartero, F.; Rojo, T.; Tendero, P.; Arias, E. 2013. An advanced 3D-model for the study and 
simulation of the pantograph catenary system, Transportation Research Part C: Emerging Technologies 36: 138-156. http://dx.doi.org/10.1016/j.trc.2013.08.004

Jarzebowicz, L.; Judek, S. 2014. 3D machine vision system for inspection of contact strips in railway vehicle current collectors, in 2014 International Conference on Applied Electronics (AE), 9-10 September 2014, Pilsen, Czech Republic, 139-144. http://dx.doi.org/10.1109/AE.2014.7011686

Facchinetti, A.; Bruni, S. 2012. Hardware-in-the-loop hybrid simulation of pantograph-catenary interaction, Journal of Sound and Vibration 331(12): 2783-2797. http://dx.doi.org/10.1016/j.jsv.2012.01.033

Kiessling, F; Puschmann, R.; Schmieder, A.; Schneider, E. 2009. Contact Lines for Electric Railways: Planning, Design, Implementation, Maintenance. Publicis Publishing. 994 p.

Luna Vázquez, C. A.; Mazo Quintas, M.; Marrón Romera, M. 2010. Non-contact sensor for monitoring catenary-pantograph interaction, in 2010 IEEE International Symposium on Industrial Electronics (ISIE), 4-7 July 2010, Bari, Italy, 482-487. http://dx.doi.org/10.1109/isie.2010.5637852

Mizan, M.; Karwowski, K.; Karkosiński, D. 2013. Monitoring odbieraków prądu w warunkach eksploatacyjnych na linii kolejowej, Przeglad Elektrotechniczny 89(12): 154-160. (in Polish).

Pombo, J.; Ambrósio, J. 2012. Influence of pantograph suspension characteristics on the contact quality with the catenary for high speed trains, Computers \& Structures 110-111: 32-42. http://dx.doi.org/10.1016/j.compstruc.2012.06.005

Pombo, J.; Ambrósio, J. 2013. Environmental and track perturbations on multiple pantograph interaction with catenaries in high-speed trains, Computers \& Structures 124: 88-101. http://dx.doi.org/10.1016/j.compstruc.2013.01.015

Pombo, J.; Ambrósio, J.; Pereira, M.; Rauter, F.; Collina, A.; Facchinetti, A. 2009. Influence of the aerodynamic forces on the pantograph-catenary system for high-speed trains, Vehicle System Dynamics: International Journal of Vehicle Mechanics and Mobility 47(11): 1327-1347. http://dx.doi.org/10.1080/00423110802613402

Rauter, F. G.; Pombo, J.; Ambrósio, J.; Chalansonnet, J.; Bobillot, A.; Pereira, M. S. 2007. Contact model for the pantograph-catenary interaction, Journal of System Design and Dynamics 1(3): 447-457. http://dx.doi.org/10.1299/jsdd.1.447

Schorno, R.; Schmidt, C.; Nietlispach, U. 2011. Zugkontrolleinrichtungen in der Schweiz, Elektrische Bahnen 109(9): 448-458. (in German).

Szeląg, A.; Maciołek, T. 2013. A 3 kV DC electric traction system modernisation for increased speed and trains power demand - problems of analysis and synthesis, Przeglad Elektrotechniczny 89(3a): 21-28.

Tanarro, F.; Fuerte, V. 2011. OHMS-real-time analysis of the pantograph-catenary interaction to reduce maintenance costs, in 5th IET Conference on Railway Condition Monitoring and Non-Destructive Testing (RCM 2011), 29-30 November 2011, Derby, UK, 1-6. http://dx.doi.org/10.1049/cp.2011.0600

Zhou, L.; Shen, Z. 2011. Progress in high-speed train technology around the world, Journal of Modern Transportation 19(1): 1-6. http://dx.doi.org/10.1007/BF03325733

Zhou, N.; Zhang, W. 2011. Investigation on dynamic performance and parameter optimization design of pantograph and catenary system, Finite Elements in Analysis and Design 47(3): 288-295.

http://dx.doi.org/10.1016/j.finel.2010.10.008 